\title{
O Ensino de Ciências e Biologia nas Escolas Públicas do Município de Miracema, Rio de Janeiro
}

\author{
Paulo Cesar Jesoé Tancredo ${ }^{1}$ (I) \& Jean Carlos Miranda ${ }^{1,2}$ (I)
}

(1) Universidade Federal Fluminense, Instituto do Noroeste Fluminense de Educação Superior, Departamento de Ciências Exatas, Biológicas e da Terra, Curso de Licenciatura em Ciências Naturais (Ênfase em Biologia), Avenida João Jasbick, Bairro Aeroporto, Santo Antônio de Pádua 28470-000, Rio de Janeiro, Brasil. E-mail: paulotancredo@id.uff.br

(2) Universidade Federal Fluminense, Instituto do Noroeste Fluminense de Educação Superior, Programa de Pós-Graduação em Ensino, Avenida João Jasbick, Bairro Aeroporto, Santo Antônio de Pádua 28470-000, Rio de Janeiro, Brasil. E-mail: jeanmiranda@id.uff.br

Tancredo P.C.J. \& Miranda J.C. (2021) O Ensino de Ciências e Biologia nas Escolas Públicas do Município de Miracema, Rio de Janeiro. Pesquisa e Ensino em Ciências Exatas e da Natureza, 5: e1769.

http://dx.doi.org/10.29215/pecen.v5i0.1769

Editor acadêmico: Diego Marceli Rocha. Recebido: 15 junho 2021. Aceito: 09 agosto 2021. Publicado: 19 agosto 2021.

Resumo: Este trabalho teve como objetivo a obtenção de dados acerca do ensino de Ciências e Biologia no município de Miracema-RJ, a fim de conhecer as condições de trabalho e os principais problemas presentes no cotidiano dos docentes. Para tal, foi elaborado um questionário, tendo como público-alvo docentes de Ciências e Biologia que atuam nos anos finais do Ensino Fundamental e no Ensino Médio da rede pública municipal e estadual, a fim de coletar dados que possibilitem: (i) delinear o perfil dos docentes de Ciências e Biologia que atuam em escolas públicas do município; (ii) conhecer e analisar a estrutura física das escolas do município e recursos didáticos disponíveis para utilização no ensino de Ciências e Biologia e (iii) detectar os problemas e desafios enfrentados pelos docentes que ministram aulas de Ciências e Biologia, no município. A presente pesquisa evidenciou a ocorrência de diversos problemas relacionados ao ensino de Ciências e Biologia. Os dados obtidos podem ser importantes para a tomada de decisões com vistas à solução dos problemas elencados e promoção da melhoria das condições de trabalho docente nas disciplinas de Ciências e Biologia.

Palavras-chave: Ensino Fundamental, Ensino Médio, Rede Pública de Ensino.

Science and Biology Teaching in Public Schools in the Municipality of Miracema, Rio de Janeiro

Abstract: This study aimed to obtain data about the teaching of Science and Biology in the municipality of Miracema-RJ, in order to learn about working conditions and the main problems present in the daily teacher's lives. To this end, a questionnaire was developed, targeting Science and Biology teachers who work in the final years of elementary school and in high school in the municipal and state public schools, in order to collect data that make it possible to: (i) outline the profile of Science and Biology teachers who work in public schools in the city; (ii) to know and analyze the physical structure as schools in the municipality and didactic resources available for use in the teaching of Science and Biology and (iii) to detect the problems and challenges faced by teachers who teach Science and Biology classes in the municipality. This research showed the occurrence of several problems related to the teaching of Science and Biology. The collected data can be important for decision-making in order to solving the listed problems and promoting the improvement of teaching working conditions in the disciplines of Science and Biology.

Key words: Elementary School, High School, Public School Network. 


\section{Introdução}

A qualidade do ensino no Brasil sempre foi alvo de questionamento por muitos setores da sociedade, que apontam governos, gestores escolares, professores, pais e responsáveis, e até mesmo alunos como culpados pelos baixos índices obtidos em avaliações nacionais e internacionais. Muitos autores (e.g., Souza et al. 2020) apontam que a educação brasileira está abaixo dos padrões aceitáveis e precisa ser repensada. Segundo dados do ano de 2018, do Programa Internacional de Avaliação de Estudantes (PISA), uma avaliação feita a cada três anos, em âmbito mundial, e que analisa o desempenho dos estudantes em três domínios (leitura, matemática e ciências), o Brasil configura na $57^{\mathrm{a}}$ posição entre 77 países avaliados no ranking educacional. Esse tipo de resultado reflete a forma como a educação básica no Brasil é tratada não só pelos governantes, mas também pela sociedade. Esse descaso, somado aos problemas políticos e sociais que o país apresenta há décadas, culminam por afetar negativamente a educação, sendo que para melhorar esse aspecto é necessário repensar políticas públicas e sociais de longo prazo.

No Brasil, o ensino de Ciências sempre esteve voltado ao atendimento das demandas sociais e econômicas do país, e fatores como desequilíbrio político e autoritarismo sempre estiveram nesse cenário afetando negativamente a expansão da área (Silva-Batista \& Moraes 2019). Na década de 1950, o ensino de ciências foi tomando forças no Brasil, mas ainda muito defasado, focado em aulas expositivas e com um material didático que não oferecia dados atualizados aos docentes e estudantes (Silva-Batista \& Moraes 2019), mesmo que a proposta do governo pregasse um maior acesso ao conhecimento científico e uma maior liberdade de pensar e agir (Pessoa 1987). Ainda na década de 1950, houve uma demanda pela produção científica impulsionada pela guerra fria. Com isso, o ensino de Ciências se voltou para a formação de cientistas e especialistas (Krasilchik 1988). Em 1961, com a promulgação da Lei n ${ }^{\circ}$ 4.024, de 1961, as aulas de Ciências passaram a ser obrigatórias em todas as séries ginasiais (atualmente Ensino Fundamental II). Com a instauração da ditadura militar em 1964, o ensino de Ciências voltou-se para a formação profissionalizante de trabalhadores e o processo de formação do cidadão associado ao ensino de Ciências foi descontinuado (Krasilchick 1988). Sob forte influência norte-americana, o ensino brasileiro foi moldado com o ideal de que a formação técnica e profissional seria a melhor opção na educação. Foi durante a década de 1970 que se começou a debater questões envolvendo "Ciência, Tecnologia e Sociedade" (CTS), onde a Ciência passa a ter seu papel social em temas como problemas ambientais e saúde, sendo tais questões levadas para dentro da sala de aula por meio das aulas de Ciências (Silva-Batista \& Moraes 2019).

A Ciência tem o importante papel de formar pessoas que entendam e questionem problemas socioambientais e que tenham a capacidade de levantar ideias e buscar soluções, e isso começa no desenvolvimento de pensamento crítico (Pires et al. 2018). Para que isso ocorra, é necessário um ensino que vá além da sala de aula, focado no cotidiano do aluno, de forma a ser possível a aplicação dos conteúdos abordados, capacitando-o para a tomada de decisões baseadas no conhecimento científico e tecnológico (Pinheiro et al. 2007). Contudo, muitos são os problemas que afetam o ensino de Ciências no Brasil. A dificuldade na realização de aulas práticas devido à falta de material, a reduzida carga horária de sala de aula e a falta de preparo do docente, dentre outros fatores, acabam por atrapalhar o desenvolvimento de um ensino dinâmico, fazendo com que o aluno limite seu pensamento aos modelos esquematizados em apostilas e livros didáticos (Interaminense 2019).

O presente trabalho tem por objetivo a obtenção de dados acerca do ensino de Ciências/Biologia nas escolas públicas da cidade de Miracema (RJ), a fim de traçar o perfil docente, conhecer suas condições de trabalho e identificar os principais problemas e desafios presentes no cotidiano escolar.

\section{Metodologia}

\section{Localidade de estudo}


Contando com uma população estimada de 27.154 habitantes (IBGE 2020), o município de Miracema, localizado na região noroeste do Estado do Rio de Janeiro, foi colonizado em meados do século XIX graças aos esforços de Ermelinda Rodrigues Pereira. Inicialmente denominada como freguesia de Santo Antônio, o distrito que à época pertencia ao município de Santo Antônio de Pádua, passou a se chamar Santo Antônio dos Brotos, devido a um evento ocorrido na capela, onde um esteio de madeira brotou, sendo esse milagre atribuído a Santo Antônio (Lima 2018). Em 1883, devido a problemas envolvendo a similaridade de nome com a Freguesia de Santo Antônio de Pádua, o local passou a se chamar Miracema, que tem origem dos termos indígenas Ybira e Cema, cujo a junção significa "pau-que-brota" (Lima 2018). Miracema se tornou independente passou à categoria de município em 1935, sendo constituída de três distritos: Miracema (Sede), Paraíso do Tobias e Venda das Flores.

A rede pública de ensino da cidade possui 19 estabelecimentos de Ensino Fundamental e sete de Ensino Médio, divididos em públicos e privados, 228 docentes no Ensino Fundamental, 145 docentes no Ensino Médio, 3.541 matrículas no Ensino Fundamental e 1.003 matrículas no Ensino Médio (IBGE 2020). As notas alcançadas pelo município no Índice de Desenvolvimento da Educação Básica (IDEB) foram de 5.5 no segundo segmento do Ensino Fundamental e 4.4 no Ensino Médio, ambas superiores às médias nacionais de 4.7 e 3.9, respectivamente (INEP 2020).

\section{Coleta de dados}

A coleta de dados foi realizada por meio de um questionário composto por 19 questões (Apêndice 1) acerca dos problemas enfrentados pelos docentes de Ciências/Biologia das redes municipal e estadual do município de Miracema. $\mathrm{O}$ questionário apresenta três seções: dados do professor, estrutura escolar e aprendizado e problemas. A primeira seção buscou investigar a formação dos professores, seu tempo de atuação em sala de aula e dados da escola em que atuam. A segunda seção aborda questões sobre a estrutura escolar, materiais e livros didáticos disponíveis. A última seção busca identificar os conteúdos de Ciências/Biologia nos quais os alunos apresentam maior dificuldade de aprendizado, e os problemas enfrentados pelos docentes, no cotidiano da sala de aula. As perguntas presentes no questionário possuem formato de múltiplas escolhas, com algumas permitindo a escolha de mais de uma opção. Nas questões com a alternativa "outros" foi disponibilizado um espaço para que os professores que optaram por essa alternativa, pudessem descrever o item correspondente à sua realidade.

Participaram docentes da área de Ciências/Biologia de sete escolas, sendo três de Ensino Médio e quatro de Ensino Fundamental. Cinco das sete escolas, estão localizadas no distrito Sede, uma em Paraíso do Tobias e uma em Venda das Flores. Inicialmente, cada escola foi visitada com a finalidade de obter autorização dos gestores para a realização da pesquisa. Nas instituições estaduais, os diretores de cada unidade foram consultados, enquanto nas instituições municipais, a autorização foi obtida junto à Secretaria Municipal de Educação. Com a pesquisa autorizada pelos responsáveis pelas instituições de ensino, os docentes foram convidados a participar e o questionário foi aplicado de forma impressa ou virtual, de acordo com a disponibilidade de cada entrevistado. Aos docentes, foi entregue o Termo de Consentimento Livre e Esclarecido da pesquisa (TCLE). Esse termo consiste em um documento que informa, esclarece e orienta sobre a natureza da pesquisa, objetivos e métodos de coleta de dados, bem como benefícios e possíveis riscos que possa acarretar. O TCLE garante o anonimato e a possibilidade de desistência do sujeito participante a qualquer momento das atividades da pesquisa. A presente pesquisa foi aprovada pelo Comitê de Ética em Pesquisa da Universidade Federal Fluminense (CAAE: 43815620.5.0000.8160; Parecer: 4.640.336). A partir das respostas do questionário aplicado, os dados obtidos foram tabulados, comparados, analisados, apresentados e discutidos, de acordo com a literatura disponível sobre os temas.

\section{Resultados e Discussão}

As respostas obtidas por meio do questionário demonstraram que todos os professores pesquisados possuem licenciatura em Ciências Biológicas; um possui uma segunda licenciatura, 
em Matemática. Ainda sobre a formação, todos os professores pesquisados afirmaram ter concluído cursos de pós-graduação; todos com pelo menos uma pós-graduação na modalidade lato sensu e dois com Mestrado Acadêmico. Estes dados indicam que os professores pesquisados possuem qualificação satisfatória para ministrar as disciplinas de Ciências e Biologia. Segundo Barbosa \& Ursi (2019), a formação do docente é um fator que tem impacto direto no ensino em sala de aula e na forma como o aprendizado do aluno é construído. Neste sentido, uma licenciatura na área se faz importante, uma vez que determinados cursos para habilitação, como por exemplo, “segunda licenciatura FORDOC”, não oferecem a formação necessária para a prática docente em sala de aula. Como apresentado na Figura 1, os professores pesquisados apresentam uma faixa etária variada, sendo: cinco (38.4\%) entre 31 a 40 anos, três $(23.1 \%)$ entre 41 a 50 anos, três $(23.1 \%)$ entre 51 a 60 anos e dois (15.4\%) com mais de 60 anos. Alguns estudos (e.g. Souza \& Gouveia 2011) apontam a idade do docente como fator importante para o ato de lecionar, sendo essa qualidade um reflexo do número de experiências vividas em sala de aula (Carvalho 2018).

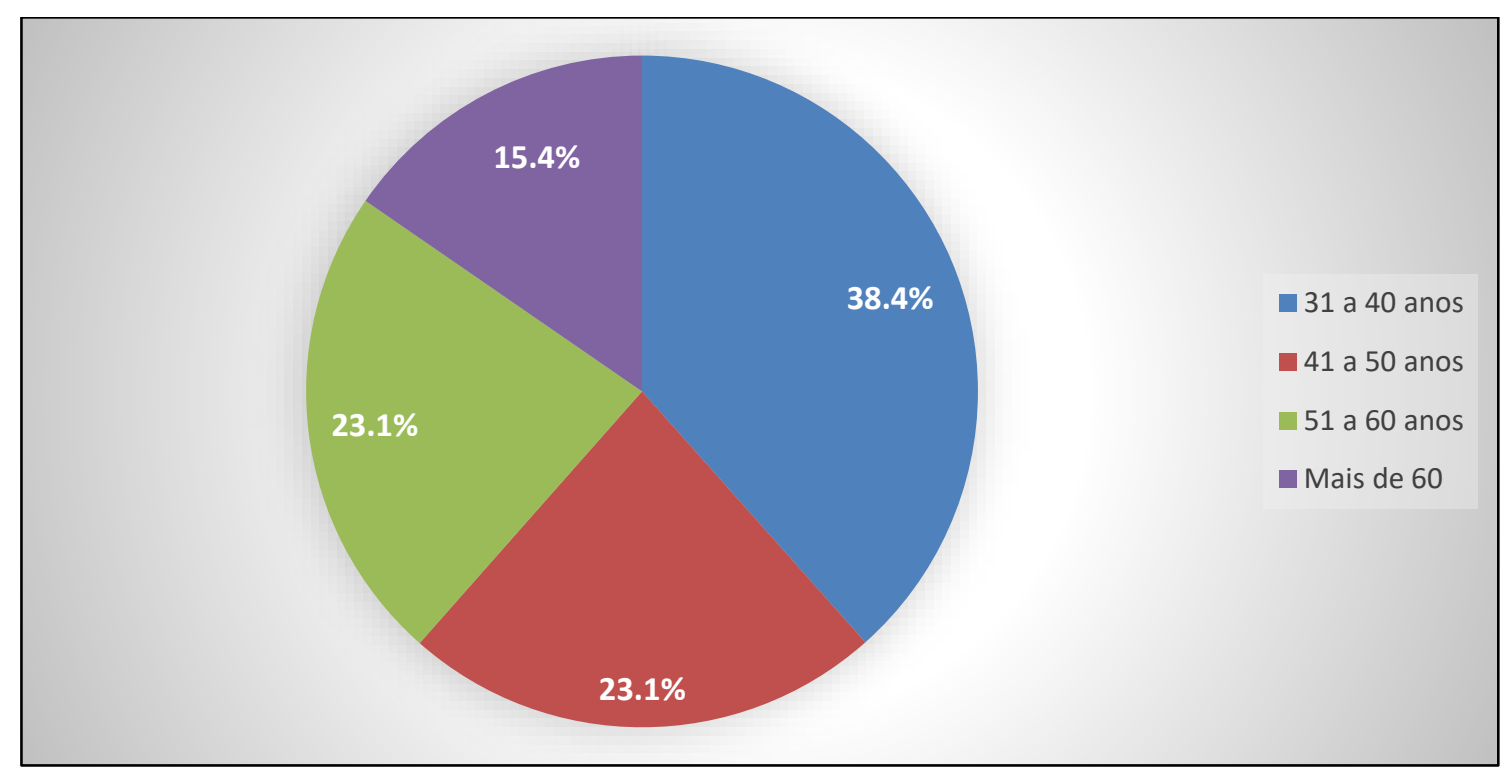

Figura 1. Faixa etária dos professores pesquisados.

A maioria dos professores pesquisados possui mais de 10 anos de experiência docente em Ciências e Biologia e somente dois possuem pouco tempo de sala de aula (Figura 2). Isso constitui outro fator positivo, uma vez que é esperado que a prática em sala de aula seja aperfeiçoada com o tempo e com as situações vivenciadas pelo professor. Conforme aponta Carvalho (2018: 41), "os saberes da experiência são construídos ao longo da prática letiva diária do professor, e constitui-se no desenvolvimento de um conjunto de competências e habilidades que vão além do conhecimento acadêmico adquirido".

Dos 13 professores pesquisados, dez trabalham apenas em escolas da rede estadual (77\%), dois trabalham em ambas as redes (15.4\%) e apenas um trabalha na rede municipal (7.6\%) (Figura 3). Sobre o número de escolas nas quais atuam, nove dos professores pesquisados (69.2\%) dividem sua jornada de trabalho entre duas escolas (Figura 4). Esse dado é importante ao avaliar o desempenho docente, uma vez que o processo de descolamento entre escola pode consumir muito tempo da rotina do professor, aumentando sobremaneira sua jornada de trabalho. Segundo Souza (2013), um professor que atende a apenas uma escola pode ter maior dedicação, o que pode refletir positivamente em seu trabalho em sala de aula.

Quatro dos professores pesquisados (30.8\%) trabalham também fora do município de Miracema (Figura 5), sendo três em Santo Antônio de Pádua, município localizado no Estado do Rio de Janeiro e um em Palma, município do Estado de Minas Gerais. Ambos os municípios são vizinhos ao município de Miracema, do qual distam cerca de $17 \mathrm{~km}$. Sete dos professores pesquisados não residem no município de Miracema. 


\section{Ensino de Ciências e Biologia em Miracema}

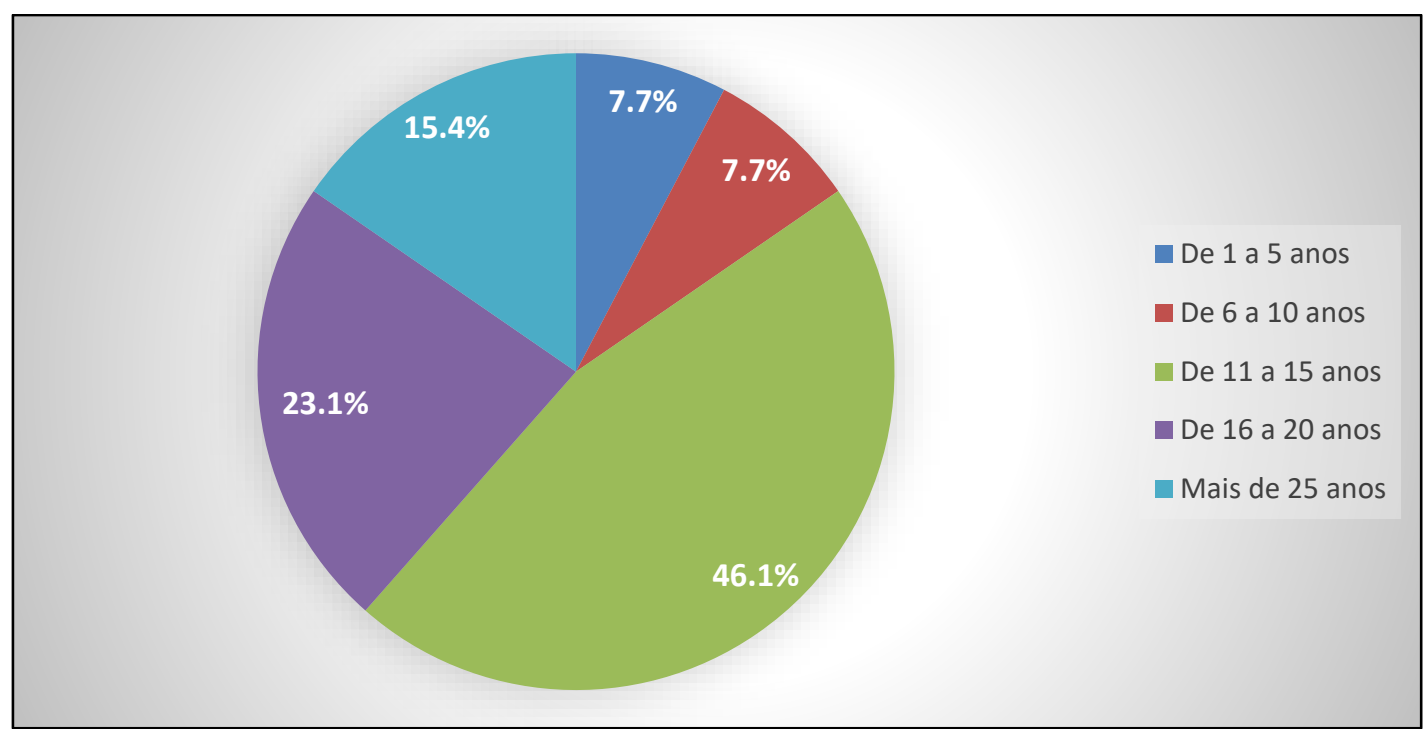

Figura 2. Tempo de atuação dos professores pesquisados, na docência em Ciências/Biologia.

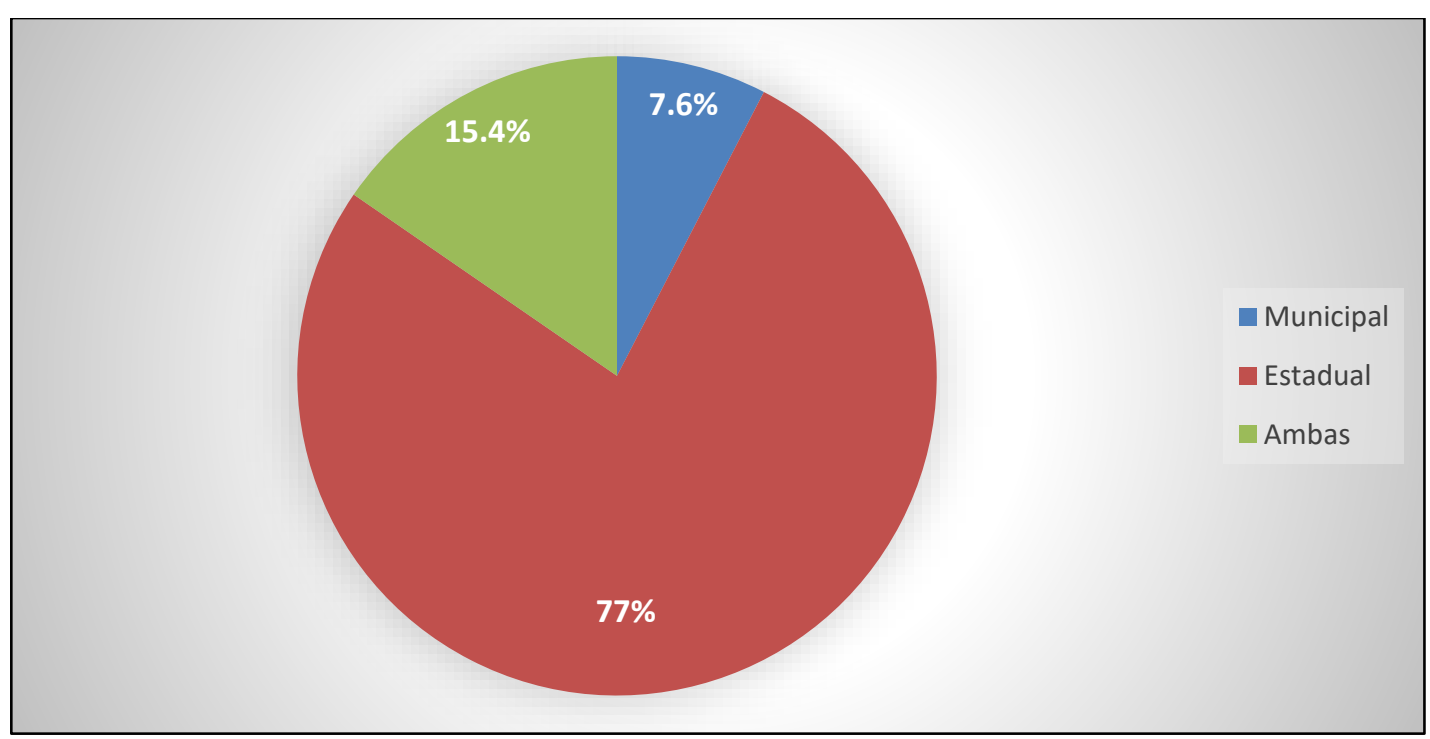

Figura 3. Redes de ensino onde atuam os professores pesquisados.

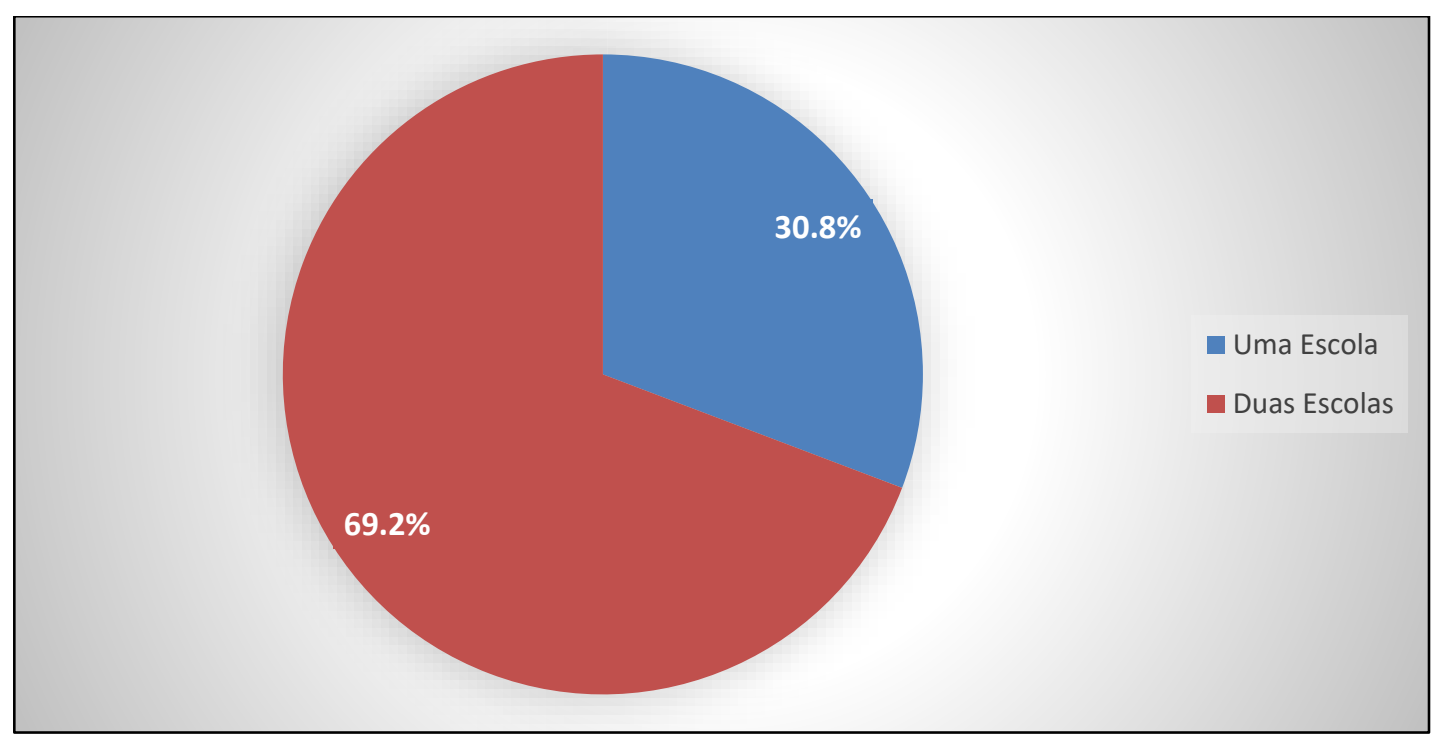

Figura 4. Número de escolas em que os professores pesquisados trabalham. 


\section{Ensino de Ciências e Biologia em Miracema}

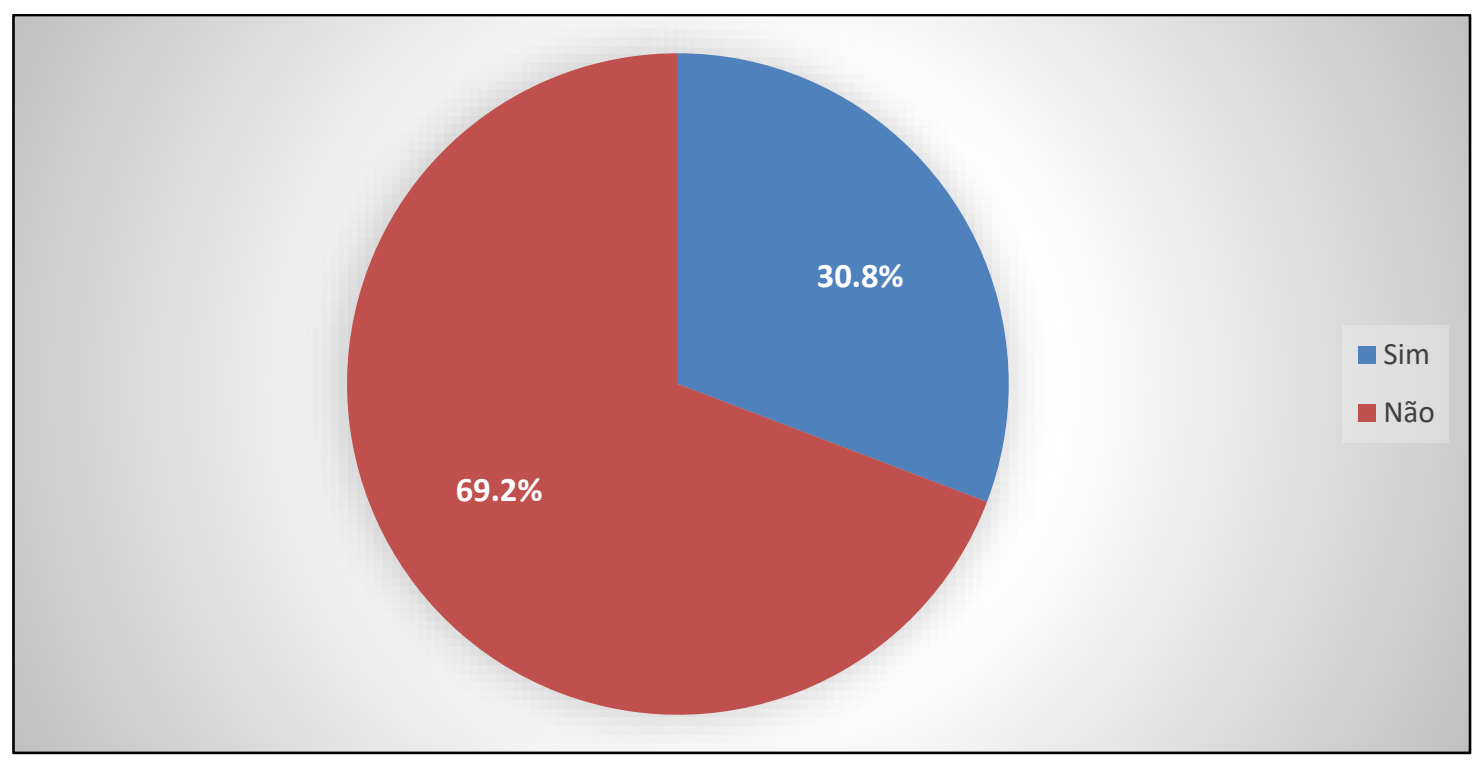

Figura 5. Sobre os professores pesquisados trabalharem em outra cidade, além de Miracema.

Visando conhecer a estrutura física disponível para ensino de Ciências/Biologia nas escolas onde atuam os professores pesquisados, foi proposta uma questão com quatro opções contendo locais dentro do ambiente escolar que podem ser utilizados como espaços de ensino. Dos 13 professores pesquisados, $10(41.7 \%)$ indicaram que as escolas nas quais trabalham possuem sala de multimídia, nove $(37.5 \%)$ que há laboratório de informática, três $(12.5 \%)$ assinalaram laboratório de Ciências/Biologia e dois (8.3\%) marcaram a opção “Outros”, informando em seguida que utilizam a biblioteca para ministrar suas aulas (Figura 6).

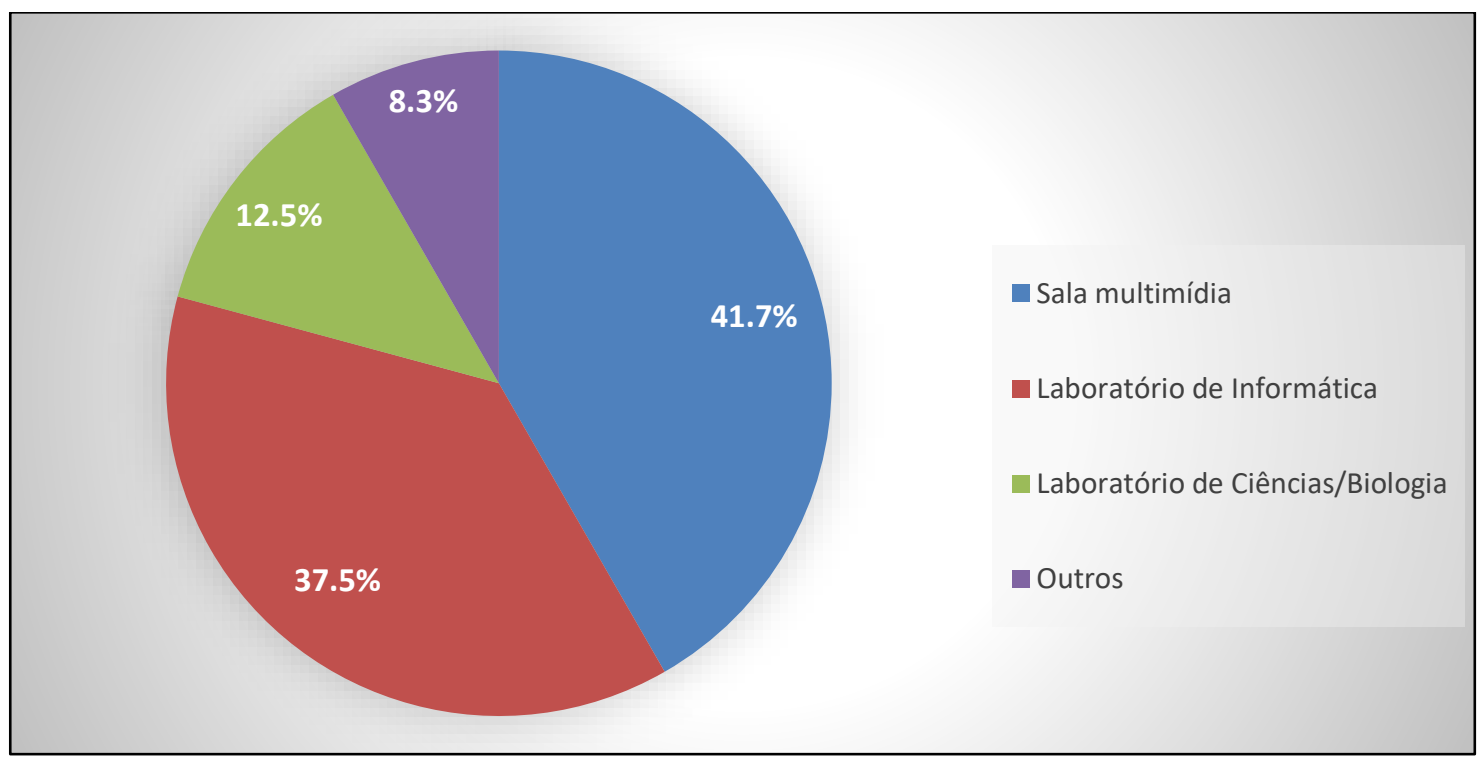

Figura 6. Espaços disponíveis para o ensino de Ciências/Biologia nas escolas do município de Miracema-RJ, nas quais atuam os professores pesquisados.

A sala multimídia presente nas escolas públicas é um local equipado com aparatos tecnológicos, tais como computador, aparelho de televisão e datashow, que permitem que o docente utilize recursos audiovisuais em suas aulas. 
No presente século, os recursos tecnológicos estão cada vez mais alinhados com a educação (Orozco 2002). Portanto, o fato de a maioria das escolas possuírem sala multimídia e laboratório de informática é um ponto positivo, uma vez que o professor tem mais um recurso para ministrar suas aulas de forma variada. No campo do Ensino de Ciências esse fator é importante, uma vez que a utilização de ferramentas multimídias e tecnológicas auxilia a concretizar conceitos científicos de uma forma didática (Silva 2015). Entretanto, a presença desses recursos na escola não é garantia de que serão utilizados; falta de manutenção dos equipamentos, turmas grandes e curto prazo de aula podem explicar sua não utilização.

O laboratório de Ciências/Biologia é uma ferramenta importante, uma vez que a experimentação é um fator essencial para a aprendizagem do aluno (Dourado 2011). Nas respostas obtidas por meio do questionário, foi possível constatar que somente duas escolas, dentre as que atuam os professores pesquisados, possuem um laboratório de Ciências/Biologia. Este é um fator negativo, dada a importância deste espaço para o ensino das disciplinas. A aula ministrada em laboratório permite que o aluno coloque em prática a teoria aprendida em sala de aula e reforça a ideia de que há um melhor desempenho na aprendizagem por meio da experiência direta (Bartzik \& Zander 2016). Cabe destacar que o laboratório de Ciências/Biologia é utilizado nas duas escolas que possuem esse ambiente, mas em uma delas somente um professor o utiliza. Entre os motivos assinalados (todos por um mesmo professor) para a não utilização do espaço estão: "pouco tempo de aula", "espaço insuficiente", material de difícil acesso", "falta de equipamento", "não sei como utilizá-lo" e "outros", onde o professor entrevistado justificou com a seguinte frase: "Por vezes a chave do laboratório fica com uma pessoa específica da escola (o horário de trabalho dela não coincide com o meu".' O que ocorre nessa escola corrobora a afirmação de que a existência de um laboratório de Ciências/Biologia na escola, não é garantia de que será utilizado por todos os professores.

Sobre os recursos didáticos utilizados, podemos observar que o livro didático é o item mais citado pelos professores pesquisados (Figura 7). Na sequência, temos filmes/vídeos, experimentos e demonstrações. Jogos didáticos, jornais e revistas e saída de campos e/ou trilhas são pouco utilizados.

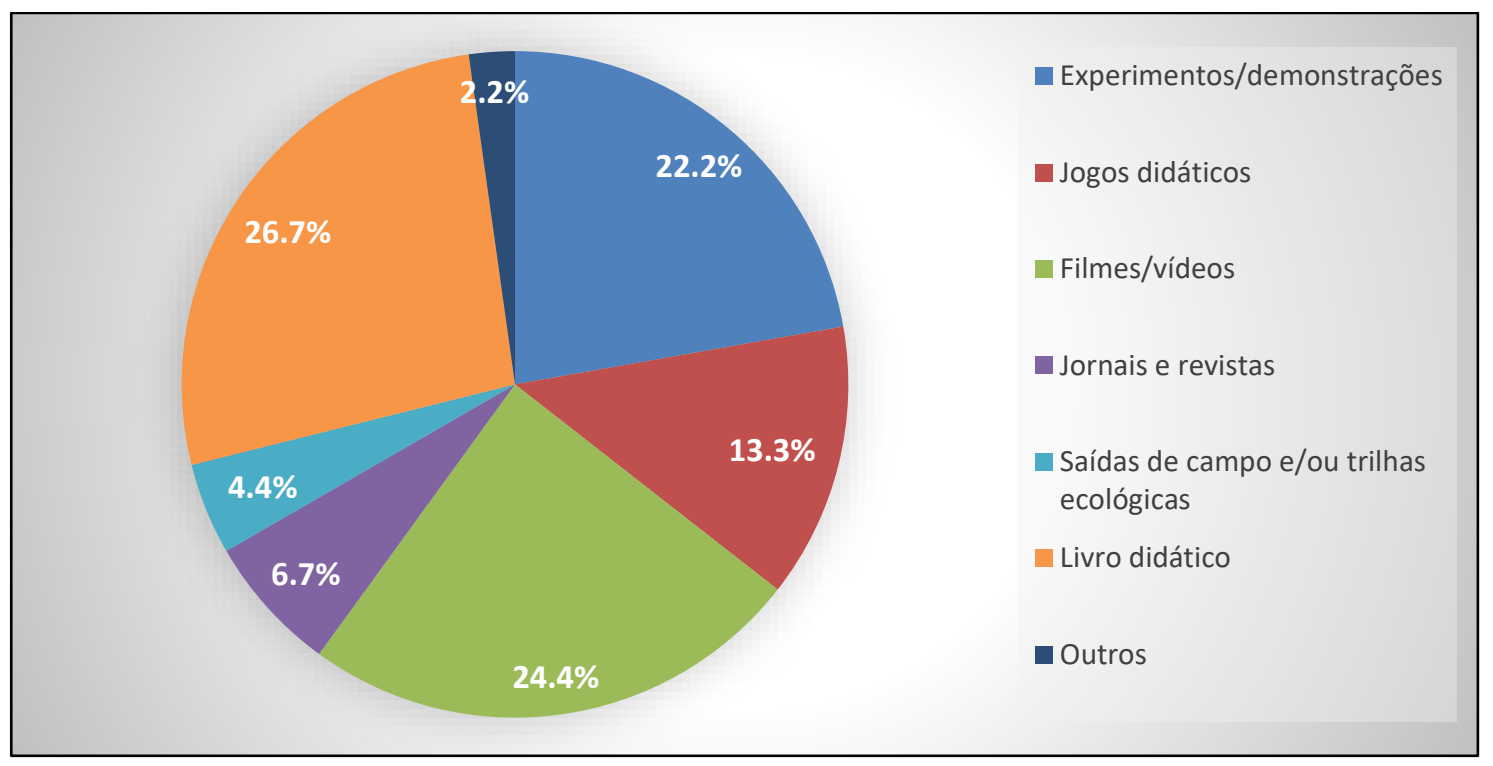

Figura 7. Recursos didáticos mais utilizados/citados pelos professores pesquisados.

Os recursos didáticos são as principais ferramentas de apoio do docente na transmissão de conhecimento. Em Ciências e Biologia, esses recursos se tornam ainda mais importantes, uma vez que essas disciplinas apresentam conteúdos que podem ser abstratos para alunos do Ensino Fundamental e Médio. Na visão do estudante, parte das disciplinas de Ciências e Biologia se baseia em nomes complexos, fórmulas intangíveis e conceitos fora da realidade (Almeida et al. 2015). 
Ciências e Biologia são disciplinas que muitas vezes não despertam interesse dos alunos, devido à utilização de nomenclatura complexa para as mesmas. Isso exige do professor que faça a transposição didática de forma adequada e também faça uso diversas estratégias e recursos. A utilização de jogos, filmes, oficinas orientadas, aulas em laboratório, saídas de campo são alguns recursos que podem ser utilizados sendo que, podem possibilitar a compreensão dos alunos no sentido da construção de conhecimentos relacionados à área (Nicola \& Paniz 2016: 358).

Portanto, o professor de Ciências e Biologia deve buscar a inovação na hora de preparar suas aulas, sempre utilizando de recursos que despertem o interesse do aluno acerca do conteúdo. Os professores pesquisados utilizam certa variedade de recursos didáticos, apesar de alguns serem pouco explorados em toda a sua potencialidade (Figura 7).

O livro didático se destaca por ser o recurso mais utilizado entre os professores pesquisados. Isso pode ser devido ao fato de ser mais acessível. A distribuição de livros didáticos ocorre por meio do Programa Nacional do Livro Didático (PNLD), instituído através do Decreto $\mathrm{n}^{\circ}$ 91.542, que proporcionou a distribuição de livros didáticos para estudantes do $1^{\circ}$ ano do Ensino Fundamental de escolas públicas (BRASIL 1985). A distribuição de livros didáticos de Ciências (Ensino Fundamental II) e Biologia (Ensino Médio) teve início em 1997 e 2007, respectivamente (Cassiano 2007). Pela presença constante nas escolas públicas, os livros acabam se tornando a principal (em muitos casos, a única) ferramenta de trabalho dos professores, que o fazem de guia para planejamento e aplicação de suas aulas (Silva 2012). É claro que o livro deve ser usado como ferramenta auxiliar, mas o professor não deve se prender a esse instrumento de forma desmedida.

A utilização de filmes e vídeos como recurso didático também se fez presente na prática docente dos professores pesquisados. Conteúdo audiovisual pode ser utilizado para despertar nos alunos a curiosidade e o interesse sobre fatos científicos (Barros \& Costa 2014). Miranda et al. (2005: 1) pontuam que "desde os primórdios da produção cinematográfica a indústria do cinema sempre foi considerada, inclusive pelos próprios produtores e diretores, um poderoso instrumento de educação e instrução”.

O item Experimentos/Demonstrações foi bastante citado; dez dos treze professores pesquisados afirmaram utilizá-los. A experimentação no ensino de Ciências e Biologia permite que o aluno consiga desenvolver a teoria através da prática (Santos 2014). Contudo, cabe destacar que tais atividades devem promover não somente a prática, mas também a reflexão acerca dos temas trabalhados. A interpretação dos acontecimentos que envolvem o experimento, assim como seu resultado obtendo sucesso ou falha, deve ser usado como forma de construção do aprendizado científico (Pereira 2010).

Uma dificuldade associada às atividades práticas é o espaço disponível para sua realização. Os professores pesquisados utilizam outras dependências da escola, e não apenas o laboratório, para a realização de aulas práticas demonstrativas (Figura 8). Um dos professores pesquisados assinalou a alternativa “outros”, justificando sua resposta com a frase: “Em outros espaços que ele possa levar e trazer o aluno dentro do horário da sua aula (sendo expressamente obrigatório comunicar a direção antes) e caso seja necessário levar um funcionário da escola como apoio. Um exemplo é Parque Ecológico de Miracema (fica muito próximo da Escola)" (sic).

Cabe ressaltar que os professores pesquisados afirmaram ter o apoio dos gestores para a realização de aulas práticas e demonstrativas; todos responderam "Sim” quando questionados se tem a liberdade para exercer aulas práticas e demonstrativas.

Jogos didáticos foram o quarto recurso mais citado pelos professores pesquisados. Alguns fatores podem explicar a pouca utilização deste recurso em sala de aula: (i) o desconhecimento, por parte dos professores pesquisados, acerca das potencialidades dos jogos didáticos; (ii) ainda serem vistos, por muitos professores, como uma forma de lazer e que não tem relação com o desenvolvimento intelectual da criança (Campos et al. 2003); (iii) a carga horária reduzida das disciplinas e (iv) a sobrecarga de trabalho do professor, que dificulta a elaboração de aulas que fujam do expositivo (Gonzaga et al. 2017). Porém, esses recursos apresentam características que permitem o envolvimento dos alunos no aprendizado, de forma que passam a desempenhar um papel mais ativo na construção do conhecimento. Segundo Fortuna (2003: 16), "enquanto joga o 
aluno desenvolve a iniciativa, a imaginação, o raciocínio, a memória, a atenção, a curiosidade e o interesse, concentrando- se por um longo tempo em uma atividade”. Nesse sentido, a utilização de jogos como recurso didático pode/deve ser mais frequente.

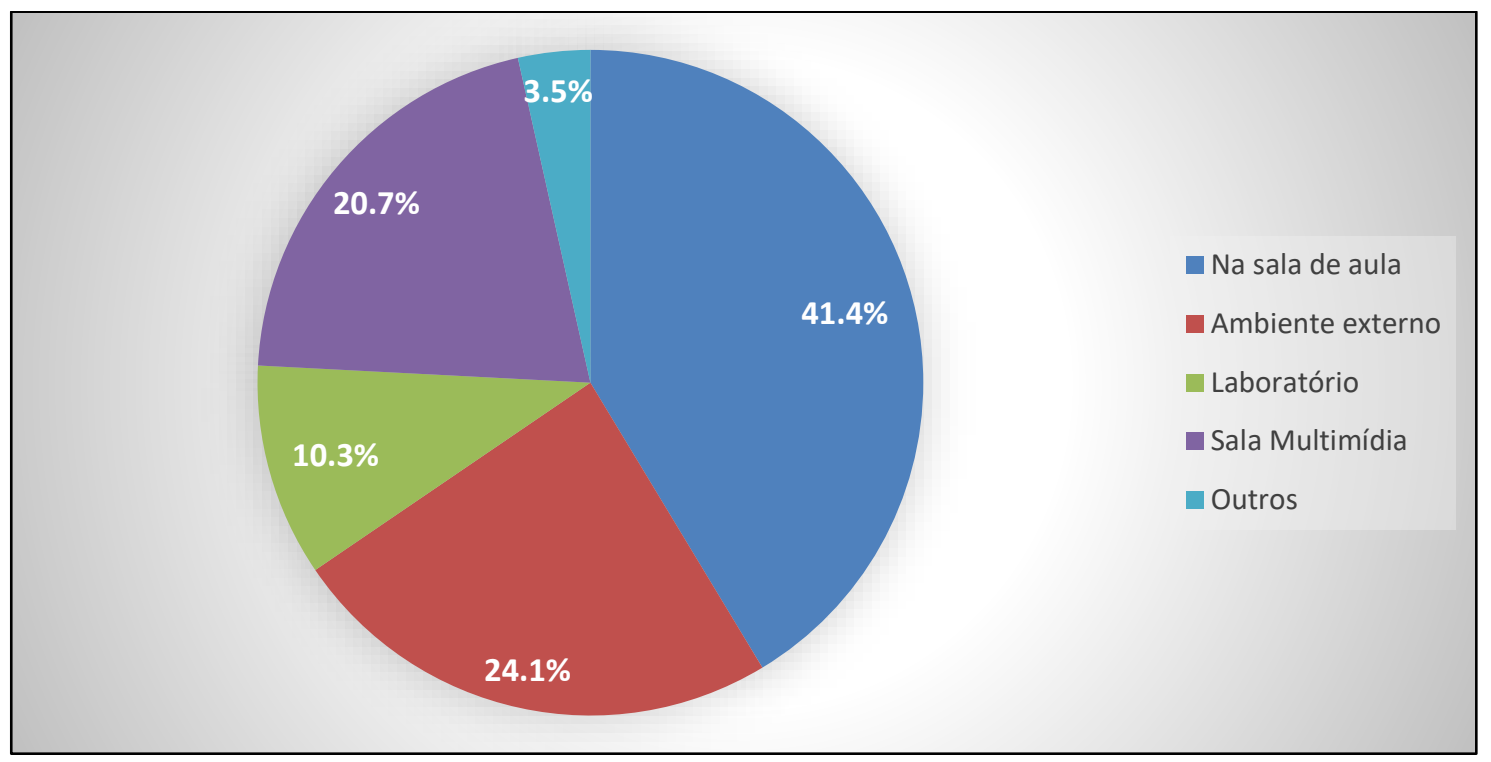

Figura 8. Locais utilizados pelos professores pesquisados para a realização de aulas práticas e demonstrativas.

O recurso Saída de Campo/Trilhas Ecológicas foi citado apenas por dois professores pesquisados, indicando que não é uma prática comum nas escolas do município. As atividades que envolvem saída de campo e passeios em ambientes fora da área escolar proporcionam uma experiência didática positiva aos alunos (Diniz \& Viveiro 2009). No município de Miracema existem locais que podem ser utilizados para tal prática, como, por exemplo, o Parque Ecológico Dr. Walquer Oliveira e o Horto Florestal. Esse parque, popularmente conhecido como "Parque Ecológico” é classificado como uma área de preservação ambiental e lazer (Arruda 2019). Portanto, é um local adequado para a realização de atividades, como pesquisas de campo, devido à sua estrutura e composição florística e faunística. Como já citado para outros recursos, alguns fatores como tempo reduzido de aula e sobrecarga do professor podem justificar a não realização de atividades como saídas de campo e trilhas ecológicas.

No que diz respeito ao conteúdo presente nos livros didáticos, somente quatro professores pesquisados (30.8\%) assinalaram que o livro cobre totalmente o que é exigido pelos documentos oficiais (Figura 9). Entende-se como documentos oficiais, os documentos que norteiam os currículos dos sistemas de educação público e privado do Brasil, abrangendo as três etapas do ensino básico. A Base Nacional Comum Curricular (BNCC), regulamentada pelo artigo 26 da Lei de Diretrizes e Bases da Educação Nacional (LDBEN), lei N 9.394 de 1996 é o principal documento norteador (BRASIL 1996). Na rede estadual, o uso do Currículo Mínimo foi regulamentado por meio da Resolução SEEDUC N ${ }^{\circ}$ 4.866, de 14 de fevereiro de 2013, que estabeleceu a criação e a implementação de um currículo mínimo norteado pela Lei $\mathrm{N}^{\circ} 9.394$ de 1996, a ser oferecido em toda rede pública do Estado (Rio de Janeiro 2013).

Os resultados obtidos por meio da questão que aborda o conteúdo dos livros didáticos indicam que o material utilizado na rede pública não se adéqua completamente ao que é exigido por documentos oficiais. O livro didático é o material de ensino mais utilizado em sala de aula e serve como guia para os professores, sendo que em muitos casos ele representa o único material disponível (Lopes \& Vasconcelos 2012). A escolha dos livros é realizada pelos professores, em conjunto com a coordenação pedagógica da unidade escolar, de acordo com o Projeto Político Pedagógico da escola e por meio da análise dos livros aprovados pelo PNLD. Caso o livro didático não contemple todo o conteúdo, fica a cargo do professor a busca por materiais complementares, a fim de atender o que preconizam os documentos oficiais, como o Currículo Mínimo, por exemplo. 


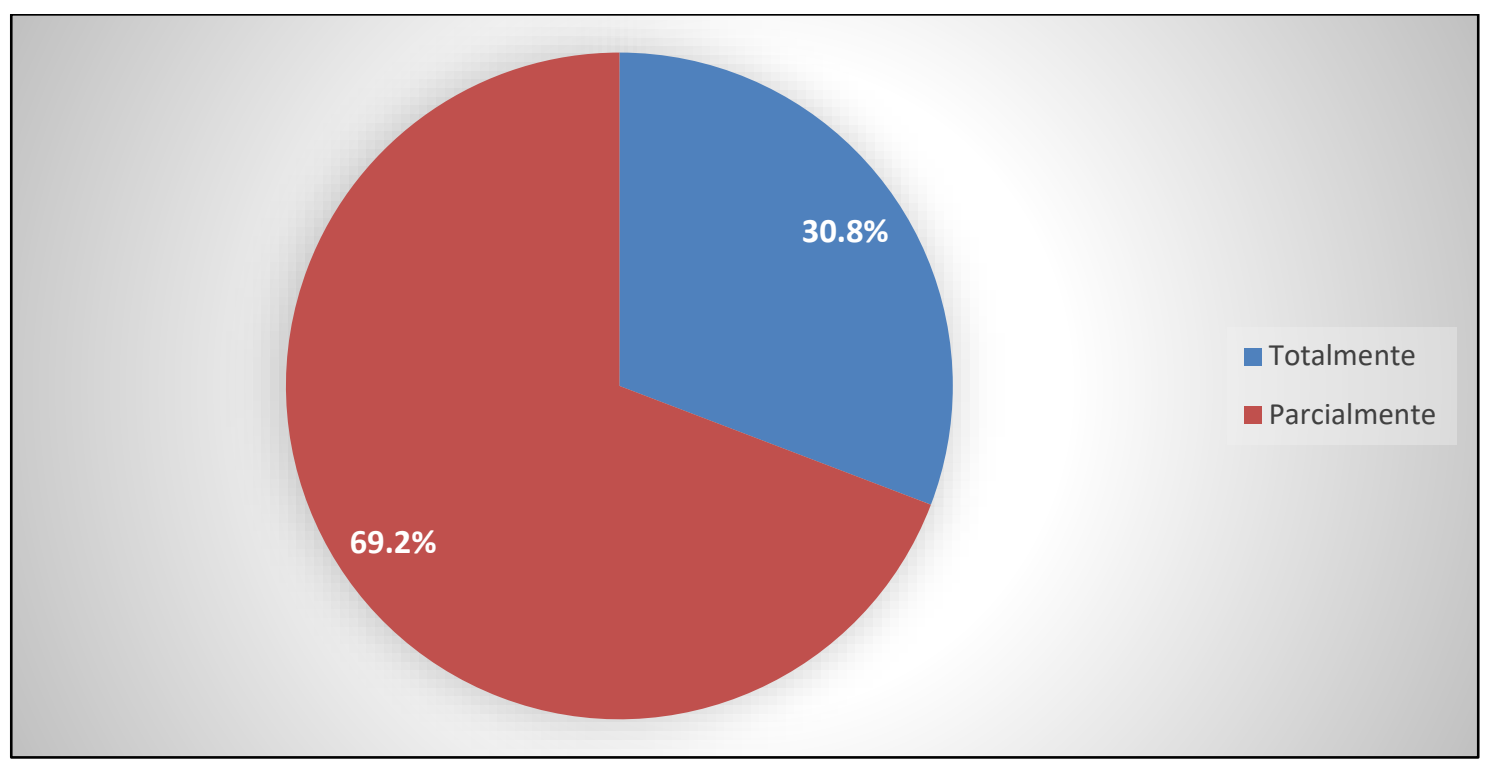

Figura 9. Cobertura dos conteúdos pelos livros didáticos utilizados pelos professores pesquisados.

Questionados sobre quais componentes curriculares os alunos apresentam maior dificuldade, os professores pesquisados indicaram aqueles relacionados à Física e à Química $(42.9 \%$, cada) (Figura 10).

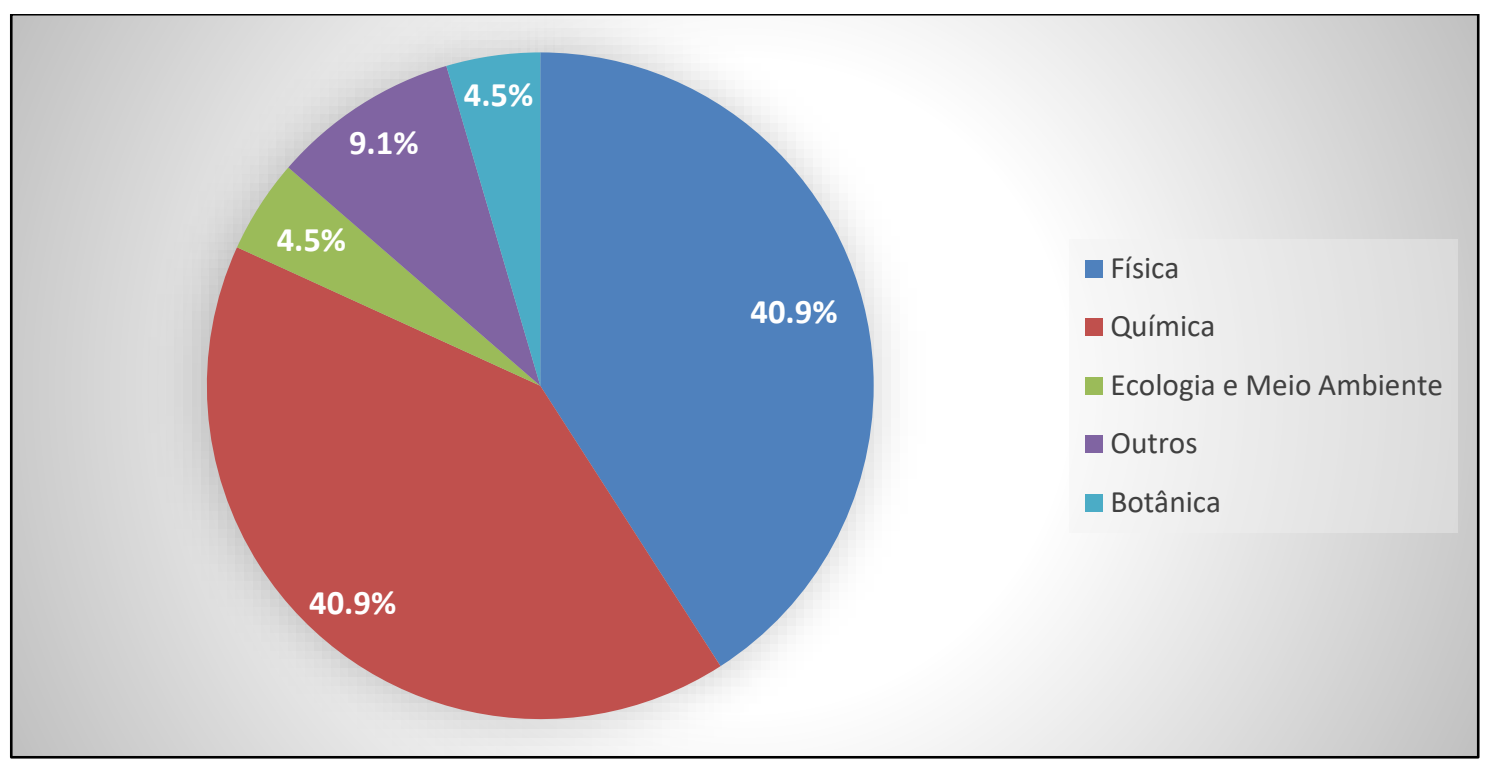

Figura 10. Conteúdos de Ciências e Biologia em que os alunos apresentam maior dificuldade.

Segundo Silva (2011), a dificuldade na disciplina de Química ocorre por ela ser abstrata e complexa, onde a visão do aluno se resume a decorar fórmulas e equações químicas. Pacheco \& Paz (2010) defendem que os alunos não entendem o motivo de estudar Química, o que acaba por dificultar o aprendizado. A metodologia utilizada pelos professores também é um fator que pode influenciar nesse resultado. O êxito no ensino de Química tem como base a experimentação, trazendo a realidade para conceitos abstratos (Rocha \& Vasconcelos 2016). Como já mencionado, todos os professores entrevistados possuem licenciatura em Ciências Biológicas, portanto, não possuem uma formação adequada para lecionar Química. Por meio do parecer $\mathrm{N}^{\circ} 134 / 2010$ do Conselho Estadual de Educação, fica aprovado o aproveitamento de professores licenciados em Biologia para ministrar aulas de Química, a fim de sanar o déficit profissional (Rio de Janeiro 2010). Esse pode ser mais um fator que explique a dificuldade dos alunos em conteúdos desta disciplina. 
O aprendizado da Física está ligado a capacidade de interpretação do aluno e do conhecimento sobre Matemática (Antonowiski et al.2017). A falta de conhecimento prévio desses dois requisitos pode ser a causa da dificuldade em relação dos conteúdos de Física. A falta de aulas práticas é outro fator a se destacar, uma vez que um método que conta somente com aulas expositivas não é adequado dentro do ensino de Física (Ribeiro 2005).

Física e Química são lecionadas no âmbito da disciplina de Ciências no Ensino Fundamental. No Ensino Médio, ambas são ofertadas separadamente. Segundo Araújo (2015), essa mudança brusca acaba por prejudicar a formação do conhecimento científico sobre essas disciplinas por parte do aluno.

A última pergunta presente no questionário aborda os problemas enfrentados pelos professores em seu cotidiano escolar. A questão apresentou 42 sinalizações, indicando que cada professor assinalou, em média, três opções. A opção "Falta de apoio familiar" foi a mais citada $(31 \%)$. Os problemas citados divergem em suas origens, mas todos são importantes entraves para o bom andamento do processo educacional.

Segundo o artigo 205 da Constituição Federal de 1988, a educação é direito de todos e dever do Estado e da família (BRASIL 1988). Portanto, o apoio familiar é um fator decisivo no pleno desenvolvimento educacional da criança e do adolescente. Durante o processo de aprendizado de seus filhos, os pais precisam construir uma relação com a escola, e essa união auxilia no desenvolvimento estudantil (Biet \& Soares 2018). O fato de todos os professores pesquisados sinalizarem a falta de apoio familiar em suas turmas revela uma situação preocupante, uma vez que, como destacam Freitas \& Ximenes (2019), as famílias têm importante papel na vida acadêmica de crianças e adolescentes.

Algumas medidas podem ser adotadas pelas escolas a fim de melhorar essa relação escolafamília. Firman et al. (2015) afirmam que reuniões de pais e mestres e conselhos escolares envolvendo os responsáveis pelos alunos podem colaborar com a valorização da presença familiar na escola. Essa aproximação é necessária visando a melhoria na qualidade da educação oferecida pela rede pública local.

A falta de interesse por parte dos alunos é outro importante fator citado. Alguns métodos não tradicionais podem ser utilizados para despertar o interesse dos alunos acerca do conteúdo trabalhado. Como observado na Figura 7, alguns professores pesquisados utilizam recursos audiovisuais, lúdicos e demonstrativos em suas aulas de Ciências e Biologia. Esses recursos podem auxiliar em despertar o interesse do estudante, uma vez que fogem ao modelo tradicional de ensino.

A questão salarial do docente também esteve presente entre os problemas citados. Assim como em qualquer profissão, a remuneração é um fator fundamental dentro de uma sociedade capitalista (Alves \& Pinto 2011). Segundo Rocha \& Melo (2019), as condições salarias do professor não são compatíveis com as várias funções desempenhadas pelos docentes. Essa falta de incentivo pode ter um reflexo negativo no trabalho docente. Como citado anteriormente, a baixa remuneração faz com que o docente amplie sua jornada de trabalho, lecionando em mais de uma escola (Figura 5).

Salas de aula superlotadas é um fator prejudicial tanto para alunos quanto para professores. Um grande número de alunos por turma dificulta o processo de aprendizado, gera indisciplina e problemas de saúde para o professor (Coelho et al. 2016). A Resolução 4.778, de 2012, limita o número de alunos por sala de aula nas escolas da rede estadual, sendo o máximo de 45 alunos (Rio de Janeiro 2012). Não foi localizado documento que trate da questão na rede municipal de Miracema. A importância de se destacar o número de alunos em sala de aula se deve à importância de aulas práticas nas disciplinas de Ciências e Biologia, como já mencionado anteriormente. Um grande quantitativo de alunos inviabiliza aulas em laboratórios e/ou pesquisas de campo.

\section{Considerações finais}

O presente trabalho evidenciou a ocorrência de diversos problemas relacionados ao ensino de Ciências e Biologia nas escolas públicas municipais e estaduais do município de Miracema. 
Contudo, cabe destacar o empenho dos professores pesquisados no desenvolvimento de ações que visam mitigar os efeitos das dificuldades enfrentadas no cotidiano escolar.

Mesmo com a escassez de espaços adequados, como por exemplo, o Laboratório de Ciências/Biologia, em todas as escolas, os professores pesquisados realizam atividades práticas como experimentos e demonstrações, além de utilizarem outros recursos didáticos fundamentais para o bom andamento do processo ensino-aprendizagem nas disciplinas. É premente a criação de espaços adequados para a realização de atividades práticas, bem como a disponibilização de recursos didáticos. Neste sentido, as situações ora apresentadas devem receber mais atenção dos órgãos públicos responsáveis pela administração escolar do município.

É importante ressaltar que alguns dos problemas evidenciados nesta pesquisa podem ser solucionados a partir de ações realizadas pelos professores, enquanto outros exigem ações da sociedade civil e, principalmente, do poder público. Portanto, o aumento da qualidade do ensino ofertado nas redes públicas municipal e estadual na cidade de Miracema depende de um esforço conjunto. Nesse sentido, os dados obtidos pela presente pesquisa podem ser importantes para a tomada de decisões com vistas à solução dos problemas elencados e promoção da melhoria das condições de trabalho docente nas disciplinas de Ciências e Biologia.

\section{Agradecimentos}

Agradecemos aos avaliares pelos comentários construtivos.

\section{Referências}

Almeida L.M., Costa J.B.S. \& Theodoro F.C.M. (2015) Modalidades e recursos didáticos mais utilizados no ensino de Ciências e Biologia. Estação Cientifica (UNIFAP), 5(1): 127-139.

Alves T. \& Pinto J.M.R. (2011) Remuneração e características do trabalho docente no Brasil: um aporte. Cadernos de Pesquisa, (41)143: 606-639.

Antonowiski R., Alencar M.V. \& Rocha L.C.T. (2017) Dificuldades encontradas para aprender e ensinar física moderna. Scientific Eletronic Archives, 10(4): 50-57.

Araújo R.P. (2015) As dificuldades na aprendizagem de física no Ensino Médio da Escola Estadual Dep. Alberto de Moura Monteiro. Trabalho de Conclusão de Curso (Graduação em Física), Instituto Federal de Educação, Ciências e Tecnologia do Piauí, Piauí.

Arruda K.M. (2019) Botânica para além da sala de aula: o contexto local como recurso motivacional para o ensino. Dissertação (Programa de Pós-Graduação em Ensino), Universidade Federal Fluminense, Santo Antônio de Pádua, Rio de Janeiro.

Barbosa P.P. \& Ursi S. (2019) Motivação para formação continuada em Educação a Distância: um estudo exploratório com professores de Biologia. Revista Electrónica de Enseñanza de las Ciencias, 18(1): 148-172.

Barros M.D.M. \& Costa E.C.P. (2014) Luz, câmera, ação: o uso de filmes como estratégia para o ensino de Ciências e Biologia. Revista Práxis, 6(11): 81-89. https://doi.org/10.25119/praxis-6-11625

Bartzik F. \& Zander L.D. (2016) A importância das aulas práticas de ciências no ensino fundamental. @rquivo Brasileiro de Educação, 4(8): 31-38. https://doi.org/10.5752/P.2318$7344.2016 \mathrm{v} 4 \mathrm{n} 8 \mathrm{p} 31$

Biet B.P. \& Soares H.C.C. (2018) A importância da família no processo de desenvolvimento da aprendizagem da criança. Revista Cientifica Online - UniAtenas, 10(2): 1-14.

BRASIL (1985) Decreto n ${ }^{\circ}$ 91.542, de 19 de agosto de 1985. Diário Oficial da União, Brasília, DF, 20 ago. 1985. Disponível em: https://www2.camara.leg.br/legin/fed/decret/1980-1987/decreto91542-19-agosto-1985-441959-publicacaooriginal-1-pe.html (Acessado em 14/04/2021).

BRASIL (1988) Constituição da República Federativa do Brasil. Brasília, DF: Presidência da República, Disponível em: http://www.planalto.gov.br/ccivil_03/constituicao/constituicao.htm (Acessado em 14/04/2021). 
BRASIL (1996) Lei de Diretrizes e Bases da Educação Nacional. Lei $\mathrm{N}^{\circ}$ 9.394, de 20 de dezembro de 1996. Diário Oficial da União, Brasília, DF, 23 dez. 1996. Disponível: http://www.planalto.gov.br/ccivil_03/leis/19394.htm (Acessado em 14/04/2021).

Campos L.M.L., Bortoloto T.M. \& Felicio A.K. (2003) A produção de jogos didáticos para o ensino de Ciências e Biologia: uma proposta para favorecer a aprendizagem. Cadernos dos Núcleos de Ensino, 47: 47-60.

Carvalho M.R.V. (2018) Perfil do professor da educação básica. Série Documental. Relatos de Pesquisa, $\mathrm{n}^{\circ}$ 41. Brasília: Instituto Nacional de Estudos e Pesquisas Educacionais Anísio Teixeira. $67 \mathrm{p}$.

Cassiano C.C.F. (2007) O mercado do livro didático no Brasil: da criação do Programa Nacional do Livro Didático (PNLD) à entrada do capital internacional espanhol (1985-2007). Tese (Programa de Pós-Graduação em Educação: História, Política, Sociedade). Pontifícia Universidade Católica de São Paulo, São Paulo.

Coelho A.G.V., Garcia S.N.V., Borba B.T. \& Jafelice R.S.M. (2016) Ressignificando o espaço escolar por meio da modelagem matemática (p. 1-12). In: Encontro Nacional de Educação Matemática, São Paulo. Anais. São Paulo: Sociedade Brasileira de Educação Matemática.

Diniz R.E.S. \& Viveiro A.A. (2009) Atividades de campo no ensino das ciências e na educação ambiental: refletindo sobre as potencialidades desta estratégia na prática escolar. Ciência em Tela, 2(1): 1-12.

Dourado L. (2001) Trabalho prático, trabalho laboratorial, trabalho de campo e trabalho experimental no ensino de Ciências: contributo para uma clarificação de termos (p. 13-18). In: Veríssimo A., Pedrosa A. \& Ribeiro R. (Orgs). Ensino experimental de Ciências: (Re) pensar o ensino de Ciências. Lisboa: Ministério da Educação. 163 p.

Firman J.A.A, Santana S.C.R. \& Ramos M.L. (2015) A importância da família junto à escola no aprendizado formal das crianças. Colloquium Humanarum, 12(3): 123-133.

Fortuna T.R. (2003) Jogo em aula: recurso permite repensar as relações de ensino-aprendizagem. Revista do Professor, 19(75): 15-19.

Freitas L.M.G.P. \& Ximenes A.N. (2019) Principais fatores da evasão escolar na Educação Básica. Revista Projeção e Docência, 10(1): 180-195.

Gonzaga G.R., Miranda J.C., Ferreira M.L., Costa R.C., Freitas C.C.C. \& Faria A.C.O. (2017) Jogos didáticos para o ensino de Ciências. Revista Educação Pública, 17(7): 1-11.

Instituto Brasileiro de Geografia e Estatística - IBGE (2020) Portal do IBGE, 2020. Disponível em: www.ibge.gov.br (Acessado em 22/10/2020).

Instituto Nacional de Estudos e Pesquisas Educacionais Anísio Teixeira - INEP (2020) Homepage do Instituto Nacional de Estudos e Pesquisas Educacionais Anísio Teixeira. Disponível em: www.gov.br/inep/pt-br (Acessado em 16/10/2020).

Interaminense B.K.S. (2019) A importância de aulas práticas no ensino de Biologia: Uma Metodologia Interativa. Revista Id on Line, 13(45): 342-354. https://doi.org/10.14295/idonline.v13i45.1842

Krasilchik M. (1988) Ensino de ciências e a formação do cidadão. Em Aberto, 7(40): 55-60. https://doi.org/10.24109/2176-6673.emaberto.7i40.1723

Lima J.M. (2018) A questão ambiental no plano diretor do município de Miracema/RJ. Dissertação (Programa de Pós-Graduação em Desenvolvimento Regional, Ambiente e Políticas Públicas). Universidade Federal Fluminense, Campos dos Goytacazes.

Lopes W.R. \& Vasconcelos S.D. (2012) Representação e distorções conceituais do conteúdo "filogenia em livros didáticos de biologia do ensino médio. Ensaio Pesquisa em Educação em Ciências, 14(3): 149-165.

Miranda C.E.A., Coppola G.D. \& Rigotti G.F. (2005) A Educação pelo cinema. Educação e Cinema, p. 1-12.

Nicola J.A. \& Paniz C.M. (2016) A importância da utilização de diferentes recursos didáticos no Ensino de Ciências e Biologia. InFOR: Inovação e Formação, 2(1): 355-381.

Orozco G.G. (2002) Comunicação, educação e novas tecnologias: tríade do século XXI. Comunicação \& Educação, 23: 57-70. https://doi.org/10.11606/issn.2316-9125.v0i23p57-70 
Pacheco H.F. \& Paz G.L. (2010) Dificuldades no ensino - aprendizagem de química no ensino médio em algumas escolas públicas da região sudeste de Teresina (p. 1-14). In: Simpósio de Produção Científica e Seminário de Iniciação Científica, 10. Anais. Teresina: UESPI.

Pereira B.B. (2010) Experimentação no ensino de Ciências e o papel do professor na construção do conhecimento. Cadernos da FUCAMP, 9(11): 1-9.

Pessoa O.F. (1987) Como Ensinar Ciências. São Paulo: Companhia Editora Nacional. 218 p.

Pinheiro N.A.M., Silveira R.M.C.F. \& Bazzo W.A. (2007) Ciência, Tecnologia e Sociedade: a relevância do enfoque CTS para o contexto do ensino médio. Ciência e Educação, 13(1): 71-84. https://doi.org/10.1590/S1516-73132007000100005

Pires E.A.C., Junior E.J.H. \& Moreira A.L.O.R. (2018) O desenvolvimento do pensamento crítico no ensino de ciências dos anos iniciais do ensino fundamental: uma reflexão a partir das atividades experimentais. Revista Valore, 3(Ed. Esp.): 152-164.

https://doi.org/10.22408/reva302018150152-164

Ribeiro M.R. (2005) Análise das dificuldades relacionadas ao ensino de física no nível médio. Trabalho de Conclusão de Curso (Licenciatura em Física). Universidade de Uberlândia, Uberlândia.

Rio de Janeiro (2010) Parecer n ${ }^{\circ}$ 134, de 13 de julho de 2010. Diário Oficial, Rio de Janeiro, 10 AGO. 2010. Disponível em: http://www.cee.rj.gov.br/pareceres/P_2010-134_normativo.pdf (Acessado em 14/04/2021).

Rio de Janeiro (2012) Resolução $n^{\circ}$ 4.778, de 20 de março de 2012. Diário Oficial, Rio de Janeiro, 23 mar. 2012. Disponível em: http://normaseducacionaisrj.blogspot.com/2013/04/resolucao4778-2012-estrutura-das.html (Acessado em 14/04/2021).

Rio de Janeiro (2013) Resolução $\mathrm{N}^{\circ} 4.866$, de 14 de fevereiro de 2013. Diário Oficial, Rio de Janeiro, 15 fev. 2010. Disponível em: http://mminerva.blogspot.com/2013/02/resolucao-seeduc-n-4866de-14-de.html (Acessado em 14/04/2021).

Rocha F.M. \& Melo S.D.G. (2019) Carreira, remuneração e piso salarial docente na rede municipal de educação de Belo Horizonte. Educação e Pesquisa, 45: 1-19.

Rocha J.S. \& Vasconcelos T.C. (2016) Dificuldades de aprendizagem no ensino de química: algumas reflexões (p. 1-10). In: Encontro Nacional de Ensino de Química. Florianópolis: UFSC.

Santos K.P. (2014) A importância dos experimentos para ensinar ciências no ensino fundamental. Monografia (Programa de Pós-Graduação em Ensino de Ciências). Universidade Tecnológica Federal do Paraná, Medianeira, Paraná.

Silva A.M. (2011) Proposta para tornar o ensino de Química mais atraente. Revista de Química Industrial, 731: 7-12.

Silva M.A. (2012) A fetichização do livro didático no Brasil. Educação \& Realidade, 37(3): 803-821.

Silva R.E.V. (2015) A utilização de multimídias no ensino de ciências naturais. Revista Contribuciones a las Ciencias Sociales, 1(29): 1-11.

Silva-Batista I.C. \& Moraes R.R. (2019) História do ensino de Ciências na Educação Básica no Brasil (do Império até os dias atuais). Revista Educação Pública, 19(26): 1-2.

Souza A.R. (2013) O professor da educação básica no Brasil: identidade e trabalho. Educar em Revista, 29(48): 53-74.

Souza A.R. \& Gouveia A.B. (2011) Os trabalhadores docentes da educação Brasil em uma leitura possível das políticas educacionais. Arquivos Analíticos de Políticas Educativas, 19(35): 1-22.

Souza D.G., Miranda J.C. \& Souza F.S. (2020) Impactos positivos e negativos do Subprojeto PIBID Ciências Naturais na formação docente. Revista de Educação, Ciência e Cultura, 25(2): 205219. 


\section{Ensino de Ciências e Biologia em Miracema}

Apêndice 1. Questionário aplicado a professores de Ciências/Biologia que atuam no município de Miracema-RJ.

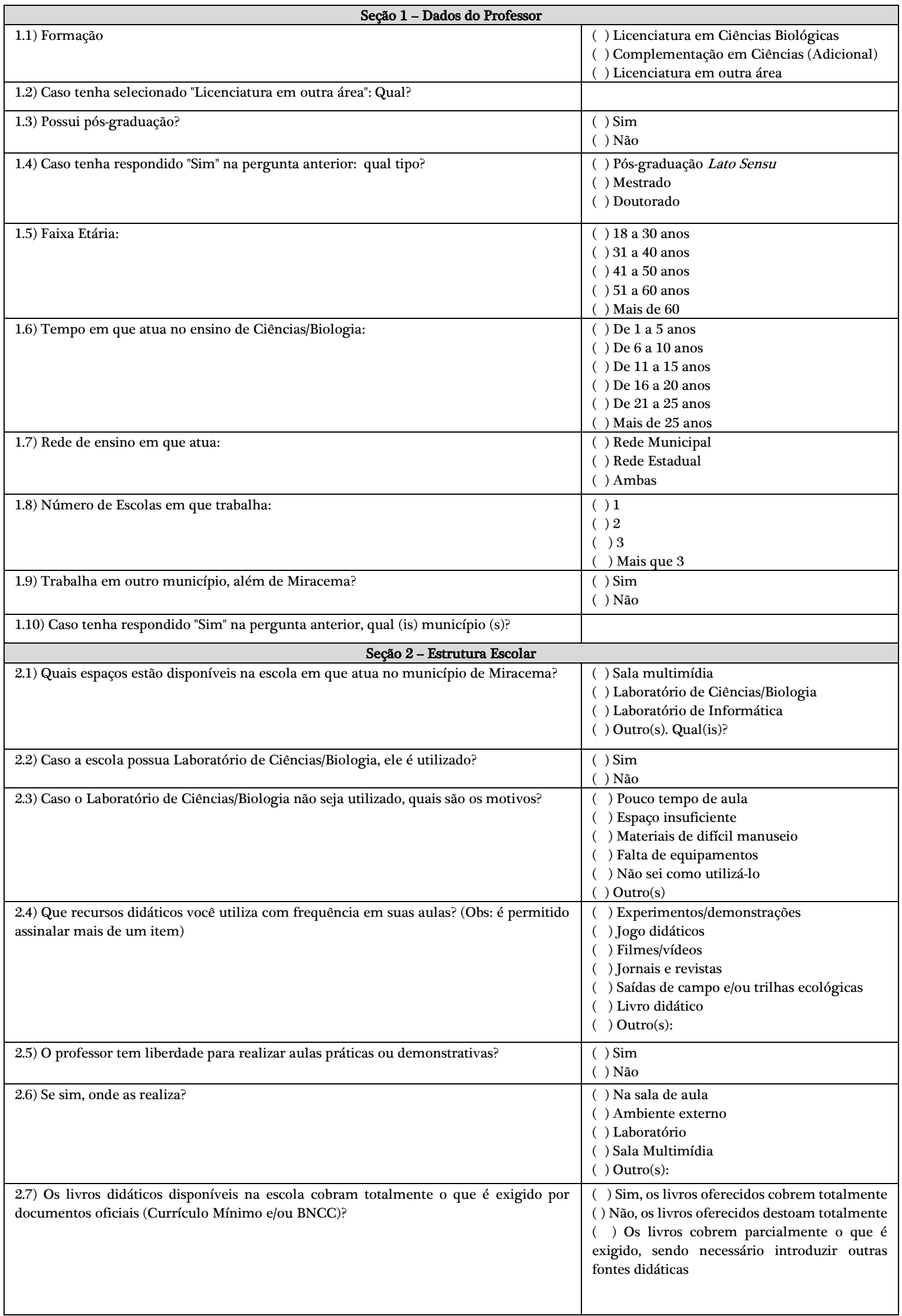




\section{Ensino de Ciências e Biologia em Miracema}

Apêndice 1. Continuação.

Seção 3 - Aprendizado e Problemas

3) Dentre os conteúdos de Ciências/Biologia, quais os seus alunos apresentam maior dificuldade de aprendizado?

Corpo Humano

( ) Seres Vivos

( ) Física

) Química

( ) Ecologia e Meio Ambiente

4) Selecione os problemas mais frequentes no seu dia a dia na sala de aula: (Obs.: é permitido assinalar mais de um item)

( ) Falta de interesse por parte dos alunos

( ) Baixa remuneração

( ) Falta de recursos didáticos

( ) Salas com grande quantitativos de alunos

( ) Falta de apoio da equipe pedagógica

( ) Falta de recursos tecnológicos

( ) Grande distorção idade-série

( ) Violência Escolar

( ) Outro(s): 